\title{
LIRIK LAGU KERONCONG SEBAGAI MEDIA PEMBELAJARAN MENYIMAK DAN BERBICARA DI HANKUK UNIVERSITY OF FOREIGN STUDIES KOREA
}

\section{KERONCONG SONG LYRICS AS LEARNING MATERIAL FOR LISTENING AND SPEAKING IN HANKUK UNIVERSITY OF FOREIGN STUDIES KOREA}

\author{
Tengsoe Tjahjono $^{1}$, M.Oktavia Vidiyanti ${ }^{2}$ \\ 1Universitas Negeri Surabaya \\ Jalan Lidah Wetan, Surabaya, Indonesia \\ 2Balai Bahasa Jawa Timur \\ Jalan Siwalanpanji, Buduran Sidoarjo, Indonesia \\ Ponsel: 082232105981;
}

Pos-el: tengsoetjahjono@unesa.ac.id,oktavia.vidiyanti@kemdikbud.go.id

\begin{abstract}
Abstrak
Lirik lagu sangat menarik dipakai sebagai media pembelajaran menyimak dan berbicara. Oleh karena itu, penelitian ini bertujuan untuk mengetahui bagaimana lirik lagu keroncong, sebagai salah satu wujud kebudayaan Indonesia, sebagai media pembelajaran menyimak dan berbicara mahasiswa yang belajar bahasa Indonesia sebagai bahasa kedua. Penelitian studi kasus ini memilih subjek penelitian mahasiswa yang memprogram mata kuliah Audio-Visual Bahasa Malay-Indonesian pada tahun pertama semester kedua di Hankuk University of Foreign Language.Untuk mengaji bagaimana langkah-langkah pembelajaran materi tersebut, data dikumpulkan melalui observasi dan wawancara. Berdasarkan hasil jawaban 15 mahasiswa atas pertanyaan dan pembahasan disimpulkan bahwa mahasiswa dapat memahami informasi dengan baik melalui apa yang diamati dan disimak dan mampu mengungkapkan pengalamannya itu secara lisan. Di samping itu mahasiswa memperoleh pengetahuan tentang budaya Indonesia yang memperkaya wawasannya tentang Indonesia.
\end{abstract}

Kata-kata kunci: lirik lagu; menyimak; berbicara; pembelajaran 


\section{Abstrak}

It is interesting to use song lyrics as a medium of learning listening and speaking. Thus, this study aims to determine how keroncong song lyrics as a manifestation of Indonesian culture can be used as a medium of listening and speaking learning for the students who learn Indonesian Language as the second language. The subjects of this case study are the students who enrolled in the Audio-Visual Malay-Indonesian Language course in the second semester of the first year in Hankuk University of Foreign Language. To examine the steps for learning the material, the data is collected through observation and interview. Based on the results and discussion, it can be concluded that the students could understand the information well through what they observ and listen to and are able to express their experiences verbally. Besides, the students obtained knowledge about Indonesian culture which enriched their insights about Indonesia.

Keywords: song lyrics; listening; speaking; learning

\section{Pendahuluan}

\section{Hankuk University of Foreign} Studies Korea memiliki Department of Malay-Indonesia Studies. Bahasa Indonesia diajarkan di jurusan tersebut. Salah satu mata kuliah yang disajikan di tahun pertama semester 1 dan 2 adalah Audio-Visual MalayIndonesian Language. Sesungguhnya mata kuliah ini merupakan mata kuliah menyimak dan berbicara berbasis IT atau berbasis media audio-visual.Mata kuliah disajikan pada tahun pertama dalam kondisi mahasiswa masih belum dapat berbahasa Indonesia sebagai bahasa asing.

Pembelajaran Bahasa Indonesia untuk penutur asing pada hakikatnya merupakan pembelajaran bahasa kedua atau pembelajaran bahasa asing. Menurut Moeller \& Catalano (2015), sebuah bahasa dianggap asing jika mayoritas dipelajari di ruang kelas dan tidak digunakan secara aktif di masyarakat tempat proses belajar berlangsung (hlm. 327). Mempelajari bahasa lain memungkinkan individu berkomunikasi secara efektif dan kreatif serta untuk berpartisipasi dalam situasi kehidupan nyata melalui bahasa dalam bungkus otentisitas budayanya. Mempelajari bahasa lain memberikan akses ke perspektif selain milik sendiri, meningkatkan kemampuan untuk melihat konten dalam koneksi lintas wilayah, dan mempromosikan perspektif 
interdisipliner sambil mendapatkan pemahaman antarbudaya.

Menurut Freeman (2000: 10) pada awalnya pembelajaran bahasa asing bertolak dari teori behavioris yang berpandangan bahwa belajar itu merupakan produk menirukan. Metode pengajaran yang populer di tahun 1950-an, disebut audio-lingual approach (ALM). ALM merupakan metode pengajaran bahasa yang sudah sejak dulu dipakai oleh guru bahasa.Metode ini menekankan pada 4 aspek yaitu peniruan, pelatihan, pengingatan, dan pengulangan. Semakin sering diulang semakin kuat pula kebiasaannya.

Chomsky (1959) dalam ulasannya terhadap Skinner (1957) mengenai perilaku verbal berpandangan bahwa bahasa itu merupakan aktivitas yang diatur oleh kaidah, bukan merupakan seperangkat kebiasaan. Menurut Chomsky psikologi stimulus-respons tidak dapat menjelaskan secara memadai kreativitas yang menghasilkanucapan baru melalui kaidah yang diinternalisasi. Pemikiran Chomsky tersebut menyebabkan kematian linguistik struktural, psikologi behavioris, dan pendekatan pembelajaran bahasa asing ALM.

Tetapi, paradigma Chomsky pun dikritisi oleh para pemikir lain. Menurut Long (1985), hendaknya input bahasa lebih mudah dipahami dengan menyederhanakannya, yaitu dengan menggunakan tanda-tanda linguistik dan ekstralinguistik, dan dengan cara memodifikasi struktur percakapan interaksional. Pada umumnya pembicara menyesuaikan bahasa mereka saat mereka berinteraksi atau menegosiasikan makna dengan orang lain. Melalui negosiasi makna, interaksi diubah dan diarahkan, menuju pada peningkatan kelengkapan. Long mengusulkan agar peserta didik, untuk memperoleh bahasa, tidak hanya cukup mendengarkan input. Mereka harus menjadi mitra kokonstruktif aktif dalam berinteraksi dan menegosiasikan jenis input yang mereka terima.

Sekarang ini pembelajaran bahasa asing bertujuan agar peserta didik mampu berkomunikasi dengan baik. Oleh karena itu, peserta didik dilatih agar memiliki kompetensi 
komunikatif. Kompetensi komunikatif merupakan kemampuan untuk mencapai tujuan komunikasi tertentu baik memakai cara linguistik maupun non-linguistik. Kompetensi komunikatif tidak terbatas pada penguasaan kompetensi gramatikal, tetapi melampui kompetensi, lebih luas dan rumit. Oleh karena itu, sungguh masuk akal jika kompetensi komunikatif dalam penguasaan bahasa asing memerlukan kerja keras dan waktu yang cukup.

Ketika berkomunikasi, manusia mereka menggunakan bahasa untuk memenuhi beberapa fungsi seperti menjelaskan, mengajak, membujuk atau memprotes, yang harus sesuai dengan konteks sosial tertentu. Komunikasi merupakan sebuah proses. Karena itulah para peserta didik tidak cukup hanya memiliki pengetahuan bentuk-bentuk bahasa, tata bahasa dan fungsi. Peserta didik harus dapat memakai bahasa untuk menegosiasikan makna dalam komunikasi, dan dapat menggunakan bahasa yang sesuai dengan konteks sosial. Pendekatan komunikatif sangat penting karena lebih menonjolkan penggunaan praktis bahasa asing daripada struktur atau tata bahasanya.

Dalam konteks pemikiran Long (1985), pembelajar bahasa asing hendaknya melakukan negosiasi atas input yang diterima. Negosiasi tersebut dapat dilakukan terhadap elemen budaya yang melekat pada bahasa tersebut, baik bahasa sasaran yang dipelajari maupun bahasa ibu mereka. Pemahaman lintas budaya akan sangat membantu peserta didik yang mempelajari bahasa asing.

Berdasarkan uraian tersebut, penelitian ini akan menelaah bagaimanakah lirik lagu, sebagai salah satu wujud kebudayaan Indonesia, dipakai sebagai media pembelajaran menyimak dan berbicara di Hankuk University of Foreign Studies Korea. Lirik lagu yang dipilih adalah lirik lagu keroncong. Alasan pemilihan lirik lagu keroncong sebagai mediapembelajaran bahasa Indonesia sebagai bahasa kedua adalah: (1) jenis musik keroncong merupakan musik asli Indonesia; (2) lirik lagu keroncong selalu mengangkat alam dan budaya Indonesia; dan (3) lagu keroncong dapat dipakai sebagai 
sarana mengenalkan Indonesia ke negara atau bangsa lain.

Lirik lagu sebagai media pembelajaran sudah banyak dilakukan. Ratminingsih (2016:36) menyimpulkan bahwa berdasarkan analisis uji empiris dengan desain before and after treatment, media audio berbasis lagu terbukti efektif meningkatkan hasil belajar bahasaInggris siswa SD. Di sisi lain, Wijayanti (2016: 145) menarik simpulan bahwa pemakaian lagu sebagai media pembelajaran bahasa Inggris membuat siswa SD antusias dalam belajar. Dalam penelitian terhadap kelas mahasiswa, Ifadah \& Aimah (2012:368) menyimpulkan bahwa mahasiswa mampu mengenali dan menjadikan lagu sebagai media belajar, bukan semata-mata sebagaihiburan. Mereka mampu menganalisis pesan dalam sebuah lagu melalui liriknya dan mampu menemukan padanan kata, serta mampu mempelajari pelafalan secara benar.

Tiga penelitian terdahulu menggunakan subjek pelajar atau mahasiswa yang mempelajari bahasa Inggris sebagai bahasa kedua.Lagu yang dipakai sebagai media tidak juga dilihat dari perspektif budayanya. Hal itu sangat berbeda dengan penelitian ini, karena tujuan penelitian ini adalah untuk menemukan efektivitas lirik lagu keroncong dalam meningkatkan kemampuan berbicara dan menyimak mahasiswa yang mempelajari bahasa Indonesia sebagai bahasa kedua dalam perspektif kebudayaan.

\section{Landasan Teori}

\subsection{Pembelajaran Bahasa Kedua}

Menurut Ellis (2003), bahasa kedua merupakan bahasa yang diperoleh atau dipelajari setelah seseorang menguasai bahasa pertama. Bahasa kedua itu dapat berarti bahasa nasional yang dikuasai setelah bahasa ibu, atau dapat pula berarti bahasa asing. Bahasa kedua tersebut dapat dikuasai melalui pemerolehan dan pembelajaran (hlm. 8). Hal itu dipertegas oleh SavilleTroike (2005) bahwa pemerolehan bahasakedua merupakan sebuah proses manusia dalam memperoleh kemahiran untuk mampu memproduksi, menangkap, serta memakai kata secara tanpa disadari, 
demi maksud berkomunikasi (hlm. 2--3). Aktivitas tersebut melibatkan kemampuan fonetik, memilih kosakata dan menyusun kalimat selain bahasa pertama, juga bahasa kedua atau bahasa target yang dipelajari.

Pemerolehan bahasa tersebut sangat bergantung kepada pendayaguna-an lingkungan pembelajaran bahasa. Dalam lingkungan bahasa tersebut peserta didik melatih kemahirannya dalam berkomunikasi, baik lisan maupun tulisan.Menurut Krashen (1981), lingkungan bahasa itu dapat berupa lingkungan formal (formal environment) dan lingkungan informal (informal environment). Lingkungan formal terikat pada silabus dan kurikulum, sedangkan lingkungan informal tidak terikat oleh hal tersebut, terjadi secara alami di luar kelas misalnya (hlm. 40).

Mahasiswa HUFS yang belajar bahasa Indonesia melakukan dua aktivitas tersebut, yaitu pemerolehan dan pembelajaran dalam lingkungan formal dan informal. Kehadiran native speaker sebagai pengajar, percakapan di luar kelas bersama native speaker, lirik lagi keroncong sebagai media, dan sebagainya merupakan upaya untuk menciptakan suasana informal supaya pembelajaran menjadi hidup, alami, dan tidak monoton.

\subsection{Menyimak dan Berbicara dalam Pembelajaran Bahasa Kedua}

Menurut Burley-Allen (1995), keterampilan menyimak merupakan keterampilan yang terlupakan. Padahal menyimak merupakan metode memperoleh informasi yang lebih banyak dipakai daripada kombinasi membaca dan menulis. Ia merupakan kanal yang sering dipakai dalam pembelajaran(hlm. 3). Ironisnya, menyimak paling tidak dipahami daripada keterampilan berbicara, membaca, dan menulis. Jika orang berpikir mengenai menyimak, mereka berasumsi secara mendasar sama dengan mendengar saja. Hal itu merupakan salah konsepsi yang mendasar sebab kemampuan menyimak yang efektif dianggap bersifat instingtif belaka. Akibatnya, orang tidak berusaha sungguh-sungguh untuk belajar dan mengembangkan kemampuan menyimaknya dan tanpa sadar 
mengabaikan sebuah fungsi komunikasi yang vital.

Dampak dari ketidakmampuan menyimak adalah kesalahpahaman, perasaan yang terluka, instruksi yang membingungkan, kehilangan informasi penting, rasa malu, dan frustrasi. Oleh karena itu, kemampuan menyimak tidak boleh diabaikan. Kemampuan tersebut harus diajarkan dan dilatihkan secara baik kepada mahasiswa, lebih dari kemampuan bahasa yang lain.

Berkomunikasi tidak hanya terbatas melakukan aktivitas menyimak, tetapi juga berbicara. Brown (1994) berpendapat bahwa menyimak dan berbicara merupakansarana bahasa pembelajar. Tanpa berbicara mustahil manusia dapat berkomunikasi satu dengan yang lain. Menurut Nunan (1995), berbicara berarti mengucapkan katakata secara lisan, berkomunikasi melalui tuturan dan ungkapan permintaan (hlm. 593). Adapun menurut Chaney \& Burk (1998), berbicara adalah proses menyusun dan membagi pesan dengan menggunakan simbol verbal dan non-verbal dalam konteks yang berbeda. Efrizal (2012) dan Nasiri \& Pourhoseingilakjani (2016) menyatakan bahwa berbicara sangat penting dalam interaksi antarmanusia pada hidup mereka sehari-hari. Berdasarkan beberapa pendapat tersebut dapat disimpulkan bahwa menyimak dan berbicara tidak dapat dipisahkan, serta berbicara merupakan salah satu kemahiran berbahasa yang sangat diperlukan manusia dalam berkomunikasi.

Mata kuliah menyimak di Hankuk University of Foreign Studies Korea diberi nama AudioVisual Malay-Indonesian Language. Deskripsi mata kuliah ini dalam website HUFS adalah melalui mata kuliah ini mahasiswa mempelajari Bahasa Melayu-Indonesia dengan penggunaan materi audio-visual yang terdiri atas praktik dikte, menonton rekaman video, dan mempelajari penggunaan situasi bahasa Melayu-Indonesia. Materi pelajaran disajikan dengan relatif mudah dimengerti karena ditujukan kepada mahasiswa baru pada tahun pertama belajar (https://builder.hufs.ac.kr/user/hufsen glish/un_2_d_4.jsp). Dalam deskripsi 
mata kuliah tersebut jelas dinyatakan bahwa audio-visual sebagai materi pembelajaran menyimak.

\subsection{Lirik Lagu sebagai Media Pembelajaran Menyimak dan Berbicara}

Brewster et al. (2002:162) menjelaskan bahwa terdapat banyak manfaat memakai lirik lagu sebagai media pembelajaran bahasa asing, terutama untuk menyimak dan berbicara. Manfaat pertama adalah bahwa lirik lagu tersebut merupakan sumber kebahasaan yang luar biasa.Melalui menyimak dan menirukan (melisankan) lirik lagu, pembelajar mengenal kata dan kalimat dalam bahasa baru. Melalui lirik lagu dan lagu, pembelajar akan lebih senang mempelajari bahasa sasaran. Lirik lagu dan lagu dimungkinkan mampu mengembangkan seluruh keterampilan berbahasa, terutama menyimak dan berbicara.

Manfaat kedua, lirik lagu merupakan sumber afektif dan psikologis. Karena lagu itu menyenangkan, maka lagu juga mampu memberikan dorongan kepada pembelajar yang sekaligus menumbuhkan sikap positif terhadap bahasa Indonesia. Bahkan, lagu sangat bermanfaat dalam peningkatan rasa percaya diri pembelajar. Ketika mereka bisa menyanyikan lagu berbahasa Indonesia, mereka akan sangat percaya diri terhadap kemampuannya berbahasa Indonesia. Manfaat ketiga, lirik lagu merupakan sumber kognitif dan pengetahuan, baik pengetahuan bahasa maupun pengetahuan budaya. Dengan lirik lagu dan lagu, pembelajar akan lebih mudah mengingat apa yang dipelajarinya.

Banyak hal yang harus diperhatikan dalam menggunakan lirik lagu sebagai media pembelajaran menyimak dan berbicara. Menurut Brewster et al. (2002) hal yang dimaksud sebagai berikut.

1. Pengajar menjelaskan konteks lagu yang akan diperdengarkan.

2. Jelaskan kata-kata sulit yang muncul dengan memakai gerakan, gambar, video, dan sebagainya.

3. Perdengarkan lagu beberapa kali melalui video yang dapat memberikan informasi secara visual, gerak, dan suara. 
4. Berikan catatan tertulis atas lagu yang diperdengarkan mengenai pesan lagu dan gambar latar yang meliputi informasi budaya dan alam.

5. Ajaklah pembelajar membandingkan dengan ragam sejenis di lingkungan bahasa ibu dan budaya mereka.

\subsection{Bahasa, Kebudayaan, dan Pembelajaran Bahasa}

Terdapat relasi timbal balik

antara bahasa, kebudayaan, dan pembelajaran bahasa. Menurut Barrow (1990:3), setiap program pembelajaran selalu melibatkan perilaku yang mungkin akan membentuk nilai dan keyakinan. Paling tidak, guru memberikan contoh dari sikap, asumsi, dan nilai tertentu.Pembelajaran bahasa Indonesia bagi penutur asing pun secara tidak langsung juga melibatkan perilaku budaya, budaya guru dan budaya bahasa target.

Valdes (1990) menjelaskan walaupun kedudukan kebudayaan dalam pembelajaran bahasa asing itu sungguh diperlukan, masih banyak pihak yang mengabaikan. Padahal faktanya kita tidak bisa menghindarkan diri dari fakta budaya dalam bahasa (hlm. 21). Valdes memberikan contoh apapun pendekatan, metode, atau teknik yang digunakan, salam biasanya disajikan pertama dalam pembelajaran bahasa asing tingkat dasar. "Salam" itu sangat kultural. Masing-masing bangsa memiliki cara mengucapkan salam yang saling berbeda. Perbedaan itu terlihat pada cara mengucapkan salam formal, salam kasual, salam kaum muda ke orang tua dan sebaliknya, dari karyawan ke majikan, dengan menggoyang tangan, membungkuk, atau menyentuh dahi, yang boleh dipanggil dengan nama depan, dan sebagainya. Hal itu tidak bersifat universal, tetapi sangat spesifik pada masing-masing komunitas etnis atau lokal.

Jadi, masing-masing bangsa memiliki keunikan budayanya yang tercermin dalam bahasa mereka. Lagu keroncong Bengawan Solo karya Gesang melukiskan keunikan budaya dan alam Indonesia.

Karena media pembelajarannya berupa video yang diunggah dalam youtube, mahasiswa di samping menyimak juga dapat 
memperoleh informasi mengenai budaya dan alam Indonesia secara visual. Media video memiliki banyak kelebihan. Menurut Sukiman (2012), media video merupakan seperangkat komponen yang mampu menyajikan gambar sekaligus suara dalam waktu bersamaan (197--188). Sementara itu menurut Arsyad (2011), media video memiliki banyak kegunaan yaitu sebagai pengganti alam sekitar dan dapat menunjukkan objek yang secara normal tidak dapat dilihat siswa karena jarak, kecil, atau proses biologis yang tidak tampak, dan sebagainya. Video juga mendorong dan meningkatkan motivasi siswa untuk bersemangat belajar (hlm. 49). Dalam konteks pembelajaran kebudayaan pada kelas pembelajaran bahasa Indonesia sebagai bahasa kedua media video dapat memanipulasi waktu dan ruang sehingga peserta didik dapat diajak berkelana ke belahan bumi mana saja walaupun dibatasi dengan ruang kelas (Uno \& Lamatenggo, 2011:135). Sadiman (2009) menyatakan media video dapat bersifat informatif, edukatif maupun instruksional (hlm. 74).

\section{Metode Penelitian}

Penelitian ini merupakan penelitian studi kasus. Subjek penelitiannya adalah mahasiswa Departemen Bahasa MelayuIndonesia Hankuk University of Foreign Studies Korea yang mengambil mata kuliah Audio-Visual Malay-Indonesian Language pada Semester 2 Tahun Pertama. Kemampuan mereka dalam bahasa Indonesia masih dalam tahap dasar. Berdasarkan keadaan mahasiswa seperti itu, pemilihan lirik lagu sebagai media pembelajaran menyimak dan berbicara akan sangat menyenangkan bagi mahasiswa. Untuk melatih keterampilan menyimak dan berbicara mahasiswa, dipilih media youtube yang mengandung materi Lagu Keroncong Bengawan Solo ciptaan Gesang dan dinyanyikan oleh Sundari Soekotjo (Soekotjo, n.d.) dalam tautanhttps://www.youtube.com/watc $\mathrm{h}$ ?v=OzhyVwkmjKw.

Youtube dapat dipilih sebagai media audio-visual. Ghaedsharafi \& Sadegh Bagheri (2012) dalam hasil penelitiannya menyimpulkan bahwa media audio visual, audio, dan visual 
berpengaruh terhadap kemampuan menulis mahasiswa di Universitas Shiraz Azad Iran. Dalam penelitian eksperimen yang telah dilakukan diperoleh hasil bahwa pemerolehan nilai media audio visual lebih tinggi dibandingkan media audio dan media visual.

Pemilihan youtube yang merupakan media audio-visual memiliki beberapa alasan, yaitu: (1) bahan pengajaran akan lebih jelas maknanya sehingga dapat lebih dipahami oleh mahasiswa; pengajaran akan lebih bervariasi, tidak semata-mata komunikasi verbal melalui penuturan dosen; dan (3) mahasiswa lebih banyak melakukan kegiatan belajar, melalui proses mengamati, melakukan, mendemonstrasikan, dan lain-lain (Harjanto, 2011:243--244).
Data yang berupa kemampuan menyimak dan berbicara mahasiswa dikumpulkan melalui observasi dan wawancara, kemudian ditelaah memakai analisis deskriptif. Observasi dilakukan pada kelas Audio-Visual Malay-Indonesian Language pada Semester 2 pada Rabu 22 Juni 2016. Peneliti mengamati proses pembelajaran yang berlangsung di kelas, mencatat peristiwa-peristiwa penting yang terjadi saat proses belajar-mengajar berlangsung. Wawancara ditujukan kepada 15 mahasiswa untuk mengetahui pemahaman mereka tentang kebudayaan Indonesia.Pertanyaan wawancara dapat dibaca dalam tabel sebagai berikut. 
Tabel 1

Pertanyaan Wawancara

\begin{tabular}{ll}
\hline No. & \multicolumn{1}{c}{ Pertanyaan } \\
\hline 1 & Apakah Anda dapat menikmati musik keroncong? \\
\hline 2 & Apakah musik keroncong itu menarik bagi Anda? \\
\hline 3 & Apakah Anda mengerti isi lagu Bengawan Solo? \\
\hline 4 & Apakah Bengawan Solo terdapat di Jawa Barat? \\
\hline 5 & Apakah kebaya hanya dipakai oleh perempuan? \\
\hline 6 & Apakah kain panjang dipakai oleh perempuan saja? \\
\hline 7 & Apakah perahu itu alat transportasi sungai? \\
\hline 9 & Apakah Indonesia memiliki banyak sungai besar? \\
\hline 10 & Apakah musik Keroncong musik asli Indonesia? \\
\hline
\end{tabular}

\section{Hasil dan Pembahasan}

\subsection{Hasil}

Menurut Sagala (2005), desain pembelajaran sebagai proses merupakan pengembangan pengajaran secara sistematik yang menggunakan secara khusus teori-teori pembelajaran unuk menjamin kualitas pembelajaran (hlm. 136). Dengan demikian dapat disimpulkan desain pembelajaran adalah praktik penyusunan media teknologi komunikasi dan isi untuk membantu agar dapat terjadi transfer pengetahuan secara efektif antara guru dan peserta didik.

Desain pembelajaran diwujudkan ke dalam sintak-sintak pembelajaran yang tersusun sebagai berikut.

Tabel 2

Sintak Pembelajaran Menyimak dan Berbicara dengan Materi Lagu Keroncong

\begin{tabular}{|c|c|c|}
\hline Sintak & Kegiatan & Keterangan \\
\hline Orientasi & $\begin{array}{l}\text { Mahasiswa diberi penjelasan bahwa } \\
\text { menyimak dan berbicara bahasa } \\
\text { Indonesia dapat dilatih melalui } \\
\text { mendengarkan musik khas Indonesia } \\
\text { yaitu keroncong. }\end{array}$ & $\begin{array}{l}\text { Lagu keroncong Bengawan Solo yang } \\
\text { disimak diunduh dari youtube. }\end{array}$ \\
\hline Menyimak & $\begin{array}{l}\text { Mahasiswa mendengarkan lagu } \\
\text { keroncong Bengawan Solo yang } \\
\text { dinyayikan oleh Soendari Soekotjo. } \\
\text { Lagu diperdengarkan selama tiga } \\
\text { kali. }\end{array}$ & $\begin{array}{l}\text { Mahasiswa mencatat bagian-bagian } \\
\text { kalimat yang penting dan kata-kata sulit } \\
\text { yang didengarkan. }\end{array}$ \\
\hline Kenal & Dosen menjelaskan aspek visual & Musik keroncong merupakan musik asli \\
\hline
\end{tabular}




\begin{tabular}{|c|c|c|}
\hline budaya & $\begin{array}{l}\text { yang terlibat dalam video yang } \\
\text { menyangkut musik keroncong, } \\
\text { busana tradisional Jawa dan perahu } \\
\text { yang melintasi Bengawan Solo. }\end{array}$ & $\begin{array}{l}\text { Indonesia. } \\
\text { Busana wanita Jawa: kain panjang, } \\
\text { kebaya, selendang, dan selop. Bentuk } \\
\text { rambut: gelung atau konde. } \\
\text { Perahu sering dipakai sebagai transportasi } \\
\text { sungai di Indonesia, misalnya di Jawa, } \\
\text { Kalimantan, Sumatera, dan Papua. }\end{array}$ \\
\hline Kena & 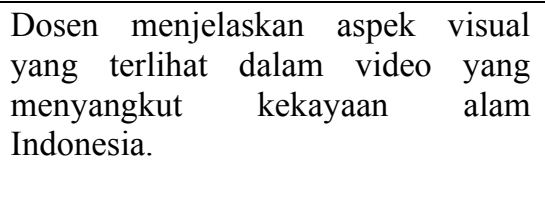 & $\begin{array}{l}\text { Bengawan Solo merupakan sungai besar } \\
\text { di Jawa, melintasi Jawa Tengah dan Jawa } \\
\text { Timur. Sumber mata air dan ikan yang } \\
\text { luar biasa, walaupun sering banjir yang } \\
\text { menggenangi daerah bantaran sungai }\end{array}$ \\
\hline $\begin{array}{l}\text { Mengerti } \\
\text { makna kata }\end{array}$ & $\begin{array}{l}\text { Mahasiswa mencatat kata-kata sulit } \\
\text { karena masih terasa baru dalam kosa } \\
\text { kata mereka. }\end{array}$ & $\begin{array}{l}\text { Kata-kata tersebut: bengawan, riwayat, } \\
\text { sedari, insani, meluap, terkurung, kaum, } \\
\text { pedagang. }\end{array}$ \\
\hline $\begin{array}{l}\text { Menjawab } \\
\text { pertanyaan } \\
\text { pendalaman }\end{array}$ & $\begin{array}{l}\text { Dosen memberikan pertanyaan: } \\
\text { 1. Bengawan Solo terletak di } \\
\text { provinsi apa saja? } \\
\text { 2. Mengapa Bengawan Solo sejak } \\
\text { dulu diperhatikan manusia? } \\
\text { 3. Apa yang terjadi jika Bengawan } \\
\text { Solo meluap? } \\
\text { 4. Mengapa kaum pedagang naik } \\
\text { perahu? } \\
\text { Bagaimana tanggapan Anda } \\
\text { tentang musik keroncong? }\end{array}$ & $\begin{array}{l}\text { Mahasiswa menjawab secara lisan. Ini } \\
\text { merupakan produk menyimak video dan } \\
\text { penjelasan dosen. }\end{array}$ \\
\hline $\begin{array}{l}\text { Pertanyaan } \\
\text { refleksi }\end{array}$ & $\begin{array}{l}\text { Dosen memberikan pertanyaan dan } \\
\text { angket yang berkaitan dengan } \\
\text { pemahaman budaya dan kekayaan } \\
\text { alam Indonesia. }\end{array}$ & $\begin{array}{l}\text { siswa menjawab semua pertanyaan } \\
\text { gket. }\end{array}$ \\
\hline
\end{tabular}

Sebenarnya empat keterampilan berbahasa, yaitu menyimak, berbicara, membaca, dan menulis pada praktik berbahasa tidak dapat dipisahkan satu dengan yang lain. Pada saat mahasiswa menonton video, empat keterampilan tersebut dapat berkelindan bekerja. Hanya saja dalam penelitian ini, hanya difokuskan kepada menyimak dan berbicara. Dalam sintaks pembelajaran, kelindan empat keterampilan itu dapat terlihat. Misalnya saja mahasiswa mendengarkan lagu, menjawab pertanyaan dosen, membaca teks berjalan dalam video, dan menulis kata-kata sulit atau mencatat bagianbagian yang penting.

Semua tahapan berlangsung dengan baik. Ada beberapa catatan penting sehubungan dengan tahapan pembelajaran tersebut. Catatan itu sebagai berikut. (1) Ternyata memutar 3 kali lagu keroncong secara langsung tidak cukup, dosen harus menghentikan sejenak untuk 
memberikan penjelasan tentang memberikan pertanyaan-pertanyaan ungkapan dan gambar visual dalam sehubungan dengan lirik lagu sebagai youtube yang menimbulkan sumber kebahasaan, sumber afeksi, pertanyaan dalam diri mahasiswa. (2) dan sumber kognisi. Dengan Dalam menjelaskan aspek visual, menyimak yang terlatih mahasiswa misalnya kebaya, konde, bengawan, harus bisa mengungkapkan sumber dan sebagainya, diperlukan media visual lain, seperti google image. (3) Mahasiswa kesulitan menuliskan katakata sulit sebab menyimak bunyi bahasa Indonesia ternyata tidaklah mudah, dosen harus membantu menulis kata-kata tersebut. (4) Ketika menjawab pertanyaan mengenai tanggapan mahasiswa tentang musik keroncong, jawaban yang muncul hanyalahbaik, saya suka, dan sangat bagus. Dosen harus membimbing agar mahasiswa memberikan alasannya.

Untuk menguji kemampuan siswa menyimak dan berbicara, dosen kebahasaan: kata, kalimat, dan tata bahasa; sumber afeksi: hormat dan mengagumi Indonesia, dan sumber kognisi: memiliki pengetahuan tentang tradisi, kebudayaan, dan alam Indonesia.

Pertanyaan refleksi dalam bentuk wawancara yang berkaitan pemahaman mahasiswa mengenai kebudayaan Indonesia melalui youtube yang ditontonnya terlihat hasil seperti dilihat pada Tabel 3 berikut ini.

Tabel 3

Hasil Wawancara tentang Pemahaman Mahasiswa tentang Kebudayaan Indonesia

\begin{tabular}{lllll}
\hline No. & \multicolumn{1}{c}{ Pertanyaan } & Ya & Tidak \\
\hline 1 & Apakah Anda dapat menikmati musik keroncong? & 14 & 1 \\
\hline 2 & Apakah musik keroncong itu menarik bagi Anda? & 14 & 1 \\
\hline 3 & Apakah Anda mengerti isi lagu Bengawan Solo? & 13 & 2 \\
\hline 4 & Apakah Bengawan Solo terdapat di Jawa Barat? & 15 & 0 \\
\hline 5 & Apakah kebaya hanya dipakai oleh perempuan? & 15 & 0 \\
\hline 6 & Apakah kain panjang dipakai oleh perempuan saja? & 10 & 5 \\
\hline 7 & Apakah perahu itu alat transportasi sungai? & 15 & 0 \\
\hline
\end{tabular}


Tengsoe Tjahjono, M. Oktavia Vidiyanti

\begin{tabular}{llll}
\hline 8 & Apakah Indonesia memiliki banyak sungai besar? & 5 & 10 \\
\hline 9 & Apakah musik Keroncong musik asli Indonesia? & 15 & 0 \\
\hline 10 & $\begin{array}{l}\text { Apakah musik keroncong banyak berisi tentang alam dan } \\
\text { budaya Indonesia? }\end{array}$ & 0 \\
\hline
\end{tabular}


Dalam jawaban pertanyaan pertama terlihat jelas bahwa 14 mahasiswa Korea tersebut dapat menikmati musik keroncong walaupun jenis musik ini baru mereka dengar. Itu berarti melodi musik keroncong memang enak didengar dan tidak terlalu rumit. Oleh karena itu, dalam menjawab pertanyaan kedua,empat belas mahasiswa secara meyakinkan merasa tertarik pada musik keroncong.

Sementara itu, tiga belas mahasiswa menjawab mengerti isi lagu Bengawan Solo.Dalam hal ini mereka mengerti informasi dan pesan yang terdapat dalam teks lagu.

Hal itu disebabkan oleh pemahaman mahasiswa mengenai forma ungkapan dan konten ungkapan.Oleh karena itu, dengan mudah 15 mahasiswa menjawab bahwa Bengawan Solo tidak terletak di Jawa Barat. Seluruh mahasiswa juga secara mudah menjawab bahwa kebaya dikenakan oleh perempuan saja, serta bahwa perahu itu merupakan alat transportasi air, musik keroncong itu asli Indonesia, dan bahwa musik keroncong selalu berisi tentang keindahan alam dan budaya Indonesia. Pengetahuan tersebut diperoleh dari penjelasan dosen.

Ketika ditanyakan perihal siapa pemakai kain panjang, 10 mahasiswa menjawab hanya perempuan, 5 mahasiswa menjawab bahwa kain panjang dapat dikenakan baik oleh perempuan maupun laki-laki.Mereka yang menjawab bahwa kain panjang hanya dikenakan oleh perempuan karena berpikir bahwa kain panjang itu merupakan bagian yang tidak terpisahkan dari kebaya.Padahal, pada kebudayaan Indonesia, banyak etnis di Indonesia yang menunjukkan bahwa kain panjang juga dikenakan oleh laki-laki. Hal itu sama dengan pemakai sarung di Indonesia, dapat laki-laki atau perempuan.

Berdasarkan hasil wawancara seperti yang tercantum dalam Tabel 3 dapat disimpulkan sebagai berikut. (1) Mayoritas mahasiswa memahami budaya Indonesia melalui youtube yang ditontonnya. (2) Mengenai kain panjang, ada perbedaan pendapat tentang siapa yang mengenakannya. (3) Mengenai sungai besar, mayoritas mahasiwa tidak 
mengetahui bahwa Indonesia banyak memiliki sungai besar di banyak pulau.

Perbedaan tersebut disebabkan

oleh: (1) mahasiswa memiliki kelemahan menyimak dan menganalisis, baik dari youtube maupun penjelasan dosen; dan (2) mahasiswa tidak memiliki pengetahuan dasar tentang kebudayaan Indonesia. Perbedaan pemahaman ini bisa terjadi karena heterogenitas mahasiswa dalam kelas.

Dalam wawancara dengan lima belas mahasiswa pemrogram mata kuliah tersebut terdapat beberapa hal yang menarik untuk dicatat. Hal yang dimaksud sebagai berikut. (1) Mahasiswa tertarik dan bersemangat mempelajari bahasa Indonesia melalui materi audio-visual. (2) Mahasiswa merasa lebih dekat dengan alam dan budaya Indonesia melalui materi audio-visual.

Mahasiswa merasakan bahwa menyimak melalui materi audiovisual seperti menyimak bahasa yang hidup. (4) Dengan mempelajari budaya Indonesia mahasiswa merasa lebih mudah mempelajari bahasa
Indonesia. (5) Bagi mahasiswa kebudayaan Indonesia bisa menjadi pintu masuk untuk mempelajari bahasa Indonesia.

\subsection{Pembahasan}

Pada bagian terdahulu sudah dijelaskan oleh Brewster et al. (2002) bahwa lirik lagu sebagai media pembelajaran menyimak dan berbicara memiliki fungsi sebagai sumberlinguistik, sumber kognitif, dan sumber afektif. Artinya, melalui lirik lagu yang diperdengarkan maka kemampuan menyimak mahasiswa menjadi baik. Pada saat mahasiswa mengungkapkan atau menjelaskan mengenai apa yang disimak, keterampilan berbicaranya juga terlatih secara baik.

Dengan menyimak lirik lagu maka mahasiswa menjalankan fungsi linguistik. Dalam fungsi linguistik tersebut mahasiswa mengembangkan kemampuan memilih dan memahami kata, ungkapan, dan idiom; menyusun frase dan kalimat; serta mengerti makna kalimat. Dalam hal ini mahasiswa diajak untuk memahami lirik lagi berikut. 
Bengawan Solo

Gesang Martohartono

Bengawan Solo, riwayatmu ini Sedari dulu jadi perhatian insani

Musim kemarau, tak seberapa airmu Di musim hujan air meluap sampai jauh

Mata airmu dari Solo, terkurung gunung seribu

Air mengalir sampai jauh, dan

akhirnya ke laut

Itu perahu, riwayatnya dulu Kaum pedagang selalu naik itu perahu

Dalam memahami makna satuan bahasa yang terdapat dalam teks lagu tersebut mahasiswa diajak mengerti dua hal, yaitu (1) forma ungkapan dan (2) konten ungkapan.
Ungkapan adalah gabungan beberapa kata yang membentuk makna khusus.Sementara itu, konten ungkapan berhubungan dengan makna yang terkandung dalam ungkapan tersebut. Forma ungkapan pada umumnya memakai diksi alam dan budaya yang memiliki relasi semantik dengan konten ungkapan tersebut.

Forma ungkapan itu dapat berbentuk kata, frasa, klausa, dan kalimat. Forma ungkapan dan maknanya tergambar dalam tabel berikut ini.

Tabel 3

Forma Ungkapan dan Maknanya

\begin{tabular}{llll}
\hline No. & \multicolumn{1}{c}{ Forma Ungkapan } & Bentuk & \multicolumn{1}{c}{ Makna } \\
\hline 1 & sedari (sejak dari) dulu & Klausa & Sejak masa lalu \\
\hline 2 & tak seberapa airmu & Klausa & Tidak begitu banyak air sungai itu. \\
\hline 3 & air meluap sampai jauh & Klausa & Banjir \\
\hline 4 & terkurung gunung seribu & Klausa & Dikelilingi banyak gunung \\
\hline 5 & kaum pedagang & Frasa & Para pedagang \\
\hline 6 & Riwayatmu & Kata & Sejarahmu \\
\hline 7 & Insani & Kata & Manusia \\
\hline 8 & mata airmu & Frasa & Sumber air \\
\hline 9 & Perahu & Kata & Kendaraan air, bermesin atau tidak \\
& & & bermesin \\
\hline 10 & musim kemarau & Frasa & Periode dalam tahun tanpa hujan. \\
\hline 11 & musim penghujan & Frasa & Periode dalam tahun yang ditandai \\
& & & dengan curah hujan tinggi. \\
\hline
\end{tabular}


Dengan memahami forma Ungkapan-ungkapan

yang ungkapan tersebut, mahasiswa lebih terdapat dalam lagu tersebut mudah memahami konten lagu itu. merepresentasikan keadaan budaya Hubungan antara lirik lagu yang dan alam Indonesia. Ungkapanmemakai bahasa sebagai instrumennya ungkapan yang mengandung konten dengan kebudayaan tak dapat budaya tergambar dalam Tabel 4 ditiadakan. Relasi bahasa dan budaya sebagai berikut. seperti dua sisi mata tuang, tidak dapat dipisahkan.

Tabel 4

Konten Ungkapan

\begin{tabular}{lll}
\hline No. & \multicolumn{1}{c}{ Ungkapan } & \multicolumn{1}{c}{ Konten } \\
\hline 1 & Bengawan Solo, riwayatmu ini & Bengawan Solo memiliki sejarah panjang. \\
\hline 2 & Kaum pedagang naik itu perahu & Indonesia sangat kaya sungai. Perahu sebagai \\
& & salah satu moda transportasi air. \\
\hline 3 & Di musim hujan air meluap sampai jauh & Kebiasaan masyarakat membuang sampah di \\
& & sungai dan sedimentasi lumpur yang tinggi \\
& & membuat sungai banjir. \\
\hline 4 & Sedari dulu jadi perhatian insani & Bengawan Solo memiliki daya tarik alamiah \\
& & dan fungsional \\
\hline
\end{tabular}

Ungkapan "Bengawan Solo, riwayatmu ini" menunjukkan bahwa Bengawan Solo memiliki sejarah yang amat panjang. Menurut Sundari (2017), Bengawan Solo sudah terbentuk 4 jutaan tahun silam. Konon, pada zaman Mataram di tenggara Desa Sala terdapat sebuah dusun bernama Nusupan yang dibelah oleh sebuah sungai besar bernama Bengawan Beton. Bengawan tersebut kemudian menjadi Bandar pelabuhan bagi para pedagang yang berlayar pulang-pergi Gresik-Surabaya. Bengawan itulah yang kemudian dikenal sebagai Bengawan Solo.

Saat menjelaskan "kaum pedagang naik itu perahu" dosen menjelaskan pula perihal sungai besar di Indonesia dan fungsinya. Dalam lagu Bengawan Solo itu dapat diketahui bahwa transportasi air sudah ada di Indonesia sejak dulu. 
Transportasi air sangat mungkin terjadi di Indonesia karena Indonesia memiliki banyak sungai besar, antara lain Sungai Kapuas (Kalimantan Barat), Sungai Mahakam (Kalimantan Timur), Sungai Barito dan Sungai Kahayan (Kalimantan Tengah), Sungai Batanghari (Jambi dan Sumatera Barat), Sungai Musi (Sumatera Selatan), Sungai Mamberamo dan Sungai Digul (Papua), dan Bengawan Solo (Jawa Tengah dan Jawa Timur). Sungaisungai besar itu digunakan sebagai sarana transportasi sungai, bahkan sebagai pasar apung.

"Di musim hujan air meluap sampai jauh" mengungkapkan bahwa hal tersebut terjadi sebagai dampak dari habitus suatu masyarakat. Ungkapan 'air meluap sampai jauh' bermakna banjir. Banjir terjadi karena sedimen lumpur semakin tebal yang berakibat pada pendangkalan sungai. Pendangkalan disebabkan oleh sampah dan lemahnya perawatan terhadap lingkungan sungai. Dalam hal ini mahasiswa juga diajak untuk memahami pentingnya mencintai dan merawat lingkungan, di samping belajar mengenai bahasa.

Ketidakpedulian terhadap lingkungan bukan hanya terjadi di Indonesia, tetapi juga terjadi di negara lain.

Baris "sedari dulu jadi perhatian insani" menunjukkan bahwa Bengawan Solo memiliki pesona, baik dari segi keindahan maupun dari segi fungsi. Keadaan itu yang membuat sungai besar itu selalu menjadi perhatian manusia. Hal itu membuktikan bahwa Indonesia memiliki pesona alam dalam sektor sungai. Seluruh sungai besar di Indonesia selalu indah. Mereka pantas menjadi tujuan wisata, layak untuk dikunjungi.

Menyimak juga mengembangkan kognisi atau pengetahuan mahasiswa, baik pengetahuan mengenai bahasa target, maupun tradisi, kebudayaan, dan alam yang diwadahi oleh bahasa tersebut. Dengan menyimak lirik lagu secara baik, mahasiswa akan mudah mengingat pengetahuan bahasa dan kebudayaan mereka.

Di samping informasi verbal, mahasiswa juga memperoleh informasi visual dari video yang 
ditontonnya. Informasi visual yang menggambarkan produk kebudayaan dan fenomena alam Indonesia

tergambar dalam tabel berikut ini.

Tabel 5

Informasi Visual

\begin{tabular}{lll}
\hline No. & Informasi Visual & \multicolumn{1}{c}{ Penjelasan } \\
\hline 1 & konde & Model rambut perempuan Indonesia, digelung atau disanggul. \\
\hline 2 & kebaya & Baju perempuan bagian atas, berlengan panjang, dipakai dengan \\
& kain panjang. \\
\hline 3 & kain panjang & Kain dalam ukuran panjang, yang kedua ujungnya tidak bertemu. \\
\hline 4 & pohon kelapa & Tumbuhan jenis palem yang berbatang tinggi, buahnya tertutup \\
& & sabut dan tempurung yang keras, di dalamnya terdapat daging \\
& & yang mengandung santan dan air, merupakan tumbuhan serba \\
& guna. \\
\hline 5 & perahu & Kendaraan air tidak bergeladak, bermesin atau tidak bermesin, \\
& & berbentuk lancip di kedua ujungnya dan lebar di bagian tengah. \\
\hline 6 & blangkon & Ikat kepala untuk pakaian tradisional laki-laki Jawa. \\
\hline 7 & rakit & Kendaraan apung yang dibuat dari beberapa bambu atau batang \\
& & pisang yang diikat berjajar, dipakai untuk mengangkut barang atau \\
& & orang di sungai besar. \\
\hline
\end{tabular}

Dengan gambar-gambar visual dalam video seperti itu mahasiswa dapat secara dekat dapat mengenal kebudayaan dan alam Indonesia.Jarak tidak lagi menjadi halangan untuk memahami Indonesia secara lebih benar. Menurut mahasiswa, belajar bahasa berbasis budaya ternyata amat efektif. Mereka dapat menyimak bunyi bahasa sekaligus melihat informasi visual dan video mengenai alam dan kebudayaan Indonesia.Mereka dapat mempelajari bahasa dan sekaligus mengenali kebudayaannya.

Berdasarkan pembahasan tersebut, pembelajaran menyimak berbasis budaya sungguh efektif memakai lirik lagu keroncong sebagai media pembelajarannya. Dengan memakai video lagu keroncong mahasiswa memperoleh informasi tentang Indonesia, baik secara verbal maupun visual. Proses pembelajaran tersebut tergambar dalam diagram berikut ini. 
Diagram 1

Proses Pembelajaran Menyimak dan Berbicara Berbasis Kebudayaan

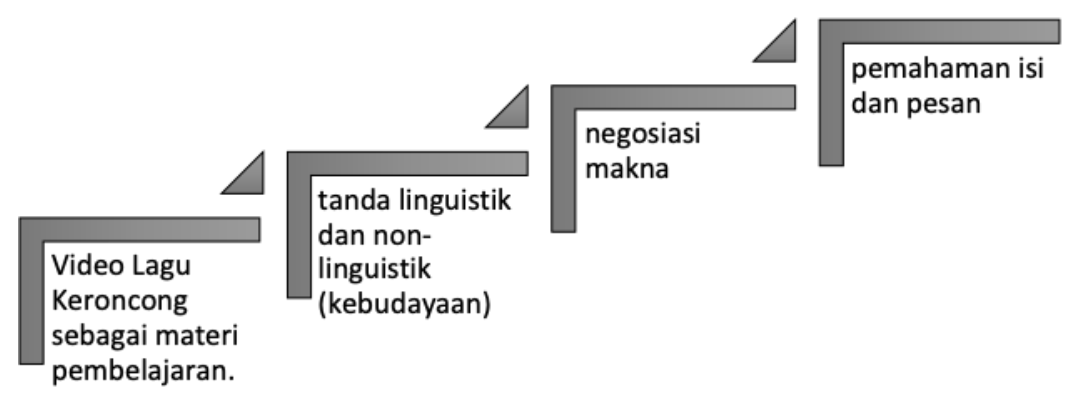

Ketika mahasiswa mendengarkan atau menyimak lagu keroncong dengan cara menontonnya di youtube ada dua hal yang diperhatikan yaitu tanda linguistik dan tanda nonlinguistik. Tanda linguistik itu disimak melalui suara atau bunyi bahasa dalam satuan-satuan bahasa. Ternyata hal itu tidak cukup. Mahasiswa juga harus memperhatikan tanda non-linguistik yang berupa tanda-tanda kebudayaan dan tanda alam. Mahasiswa tidak cukup hanya menggunakan tanda linguistik untuk memahami isi dan pesan materi komunikasi, tetapi harus mampu melakukan negosiasi makna dengan melibatkan pengetahuan kebudayaan yang didapatkan.

Hal itu sejajar dengan pendapat Brett (2000) yang menyatakan bahwa kebudayaansebagai faktor kunci dalam proses negosiasi dan komunikasi. Proses negoisasi tersebut berbeda antara kebudayaan satu dengan lainnya (Salacuse, 2005). Oleh karena itu, dalam pembelajaran bahasa Indonesia sebagai bahasa kedua atau bahasa asing mahasiswa harus memiliki pengetahuan dan pemahaman antarbudaya (cross culture understanding).

Menurut Corbett (2003), pemahaman antarbudaya bukan sekadar kemampuan berbahasa sesuai dengan penutur asli. Dalam pemahaman antarbudaya,mahasiswa Korea yang belajar bahasa Indonesia memposisikan dirinya sebagai seorang diplomat, yang mampu memandang dan berkomunikasi dalam perspektif kebudayaan yang berbeda atas dasar sudut pandang orang yang memiliki kemampuan komunikasi tersebut.

Berdasarkan hasil wawancara yang terdapat dalam Tabel 3, para mahasiswa Korea merefleksikan 
bahwa mempelajari bahasa Indonesia melalui pengetahuan kebudayaan Indonesia sungguh menarik dan menyenangkan. Menyimak lagu keroncong mendekatkan mereka pada kebudayaan Indonesia dan melatih telinga mereka untuk mendengarkan bahasa Indonesia yang hidup. Hal tersebut dilakukannya dengan penuh kesungguhan. Para mahasiswa tersebut menyadari bahwa terdapat hubungan antara bahasa, pikiran, dan kebudayaan.

Dengan demikian, melalui menyimak lirik lagu mahasiswa HUFS Korea memiliki sikap postif terhadap bahasa dan budaya Indonesia.Hal tersebut berarti bahwa mahasiswa itu telah memenuhi fungsi afektif, rasa cinta dan kagum pada bahasa dan budaya negeri ini.

Dalam akhir pembahasan ini dapat ditegaskan bahwa jangan tinggalkan materi kebudayaan dalam pembelajaran bahasa Indonesia sebagai bahasa kedua. Kebudayaan merupakan cara mudah untuk mempelajari bahasa asing.

\section{Penutup}

Berdasarkan hasil dan pembahasan dapat disimpulkan bahwa penggunaan lirik lagu sebagai media pembelajaran menyimak dan berbicara di Department of Malay-Indonesia Studies-Hankuk University of Foreign Studies Korea sangat menarik dan menyenangkan bagi para mahasiswa. Hal tersebut disebabkan: (1) lirik lagu dapat hadir sebagai sumber kebahasaan; (2) lirik lagu dapat hadir sebagai sumber pengetahuan, baik pengetahuan bahasa dan budaya; dan (3) lirik lagu dapat membangun sikap positif terhadap bahasa dan budaya Indonesia. Hal itu dibuktikan dengan kemampuan mahasiswa menjawab pertanyaan dan merefleksikan pengalamannya tentang Indonesia berdasarkan video yang ditayangkan.

Pembelajaran bahasa Indonesia sebagai bahasa kedua, baik itu pembelajaran menyimak, berbicara, membaca, dan menulis, hendaknya disajikan berbasis kebudayaan, sebab kebudayaan merupakan kata kunci untuk memahami bahasa. Pada pembelajaran bahasa Indonesia sebagai bahasa kedua dapat dipilih materi wujud kebudayaan selain lagu 
keroncong, misalnya candi, wayang, batik, gotong royong, dan sebagainya dengan memakai media audio video yang dapat diunduh dari youtube. Dalam hal ini kebudayaan memiliki dua fungsi penting, yaitu (1) jalan mempelajari bahasa Indonesia, dan (2) kunci untuk mengenalkan kekayaan Indonesia ke seluruh dunia.

\section{Daftar Pustaka}

Arsyad, A. (2011). Media Pembelajaran. Jakarta: PT Raja Grafindo Persada.

Barrow, R. (1990). "Culture, Values and the Language Classroom." In B. Harrison (Ed.), Culture and the Language Classroom. Modern English Publications in association with The British Council.

Brett, J. M. (2000). Culture and Negotiation. International Journal of Psychology, 32(2). https://doi.org/https://doi.org/10.1 080/002075900399385

Brewster, J., Ellis, G., \& Girard, D. (2002). The Primary English Teacher's Guide. England: Penguin English.

Brown, H. D. (1994). Teaching by Principles-An Interactive Approach to Language Pedagogy. New York: Prentice Hall Regents.

Burley-Allen, M. (1995). Listening The Forgotten Skills: A Self
Teaching Guide. New York: John Wiley \& Sons, Inc.

Chaney, A. L., \& Burk, T. L. (1998). Teaching Oral Communication in Grades K-8. Boston: Allyn and Bacon.

Chomsky, N. (1959). "Review of Verbal Behavior by B.F. Skinner." Language, 35, 26-58.

Corbett, J. (2003). An Intercultural Approach To Second Language Education. In J. Corbett (Ed.), An Intercultural Approach to English Language Teaching. Clevedon, England: Multi-lingual Matters.

Efrizal, D. (2012). Improving Students' Speaking through Communicative Language Teaching Method at Mts Ja-alhaq, Sentot Ali Basa Islamic Boarding School of Bengkulu, Indonesia. International Journal of Humanities and Social Science, 2 (20), 127-134.

Ellis, R. (2003). Second Language Acquistion. New York: Oxford University Press.

Freeman, L. (2000). Techniques and Principles in Language Teaching. Oxford: Oxford University Press.

Ghaedsharafi, M., \& Sadegh Bagheri, M. (2012). Effects of Audiovisual, Audio, and Visual Presentations on EFL Learners' Writing Skill. International Journal of English Linguistics, 2 (2), 113-121. https://doi.org/10.5539/ijel.v2n2p 113 
Harjanto. (2011). Perencanaan Pengajaran (Delapan). Jakarta: Rineka Cipta.

Ifadah, M., \& Aimah, S. (2012). Keefektifan Lagu sebagai Media Belajar dalam Pengajaran Pronounciation/Pengucapan. In Seminar Hasil-Hasil PenelitianLPPM UNIMUS (pp. 363-370).

Krashen, S. (1981). Second Language Acquisition and Second Language Learning. University of Southern California, California: Pergamon Press Inc.

Long, M. H. (1985). "Input and Second Language Acquisition Theory." In S. Gass \& C. Madden (Eds.), Input in Second Language Acquisition (pp. 377-393). Rowley, Mass: Newbury House.

Moeller, A. J., \& Catalano, T. (2015). Foreign Language Teaching and Learning. International Encyclopedia of the Social \& Behavioral Sciences: Second Edition, 327-332. https://doi.org/10.1016/B978-008-097086-8.92082-8

Nasiri, A., \& Pourhoseingilakjani, A. (2016). A Review of EFL Learners' Speaking Skill and the Strategies for Improvement. Modern Journal of Language Teaching Methods, 6 (9), 53-59. Retrieved from https://mjltm.org/article-1-65en.pdf

Nunan, D. (1995). Language Teaching Methodology: A Textbook for Teachers. New York: Phoenix
Ltd.

Ratminingsih, N. M. (2016). Efektivitas Media Audio Pembelajaran Bahasa Inggris Berbasis Lagu Kreasi di Kelas Lima Sekolah Dasar. Jurnal Pendidikan Indonesia, 5 (1), 2738. https://doi.org/10.23887/jpiundiksha.v5i1.8292

Sadiman, A. S. (2009). Media Pendidikan. Jakarta: PT Raja Grafindo Persada.

Sagala, S. (2005). Konsep dan Makna Pembelajaran. Bandung: Alfabeta.

Salacuse, J. W. (2005). Negotiating: The Top Ten Ways That Culture Can Affect Your Negotiation. Ivey Business Journal, 69(4). Retrieved from https://iveybusinessjournal.com/p ublication/negotiating-the-topten-ways-that-culture-can-affectyour-negotiation/

Saville-Troike, M. (2005). Introducing Second Language Acquisition. New York: Cambridge University Press.

Skinner, B. F. (1957). Verbal Behavior. London: Methuen.

Soekotjo, S. (n.d.). Bengawan Solo Sundari Soekotjo (Official Video). Gema Nada Pertiwi. Retrieved from

https://www.youtube.com/watch? $\mathrm{v}=$ csyYxUG6RQI

Sukiman. (2012). Pengembangan Media Pembelajaran. Yogyakarta: Pedagogia. 
Sundari, D. (2017). Asal Mula Nama Sungai Bengawan Solo. Retrieved December 22, 2019, from

https://www.kompasiana.com/de wisundari/5962dc557460f03c101 f72c2/asal-mula-nama-sungaibengawan-solo

Uno, H. B., \& Lamatenggo, N. (2011). Teknologi Komunikasi dan Informasi Pembelajaran. Jakarta:
Bumi Aksara.

Valdes, J. (1990). "The Inevitability of Teaching and Learning Culture in a Foreign Language Course." In Culture and the Language Classroom. Modern English Publications in association with The British Council. 